\title{
Gradation in modified AdjPs *
}

\author{
Elena Castroviejo-Miró \\ Spanish National Research Council \\ (CCHS-CSIC)
}

\begin{abstract}
The goal of this paper is to gain a better understanding of the composition processes underlying DegPs headed by how that include an adjective that is in turn modified. These include how extremely high, how politically incorrect and how damn important. The focus here is on adverbs such as extremely, which have been used in the literature on exclamatives as a test of exclamativity, but which have not been given to this date a compositional semantics. I argue that, even if this has been challenged in the literature for Remarkably adverbs such as surprisingly, extremely is a degree predicate, where degrees are not construed as positive numbers on a scale, but rather as equivalence classes of individuals (Cresswell 1976). This research has interesting ramifications for the analysis of degree expressions (how and so vs. very and enough) and for the distinction between interrogative and exclamative clauses.
\end{abstract}

Keywords: modification, gradability, adverbs, adjectives, $w h$-interrogatives, $w h$-exclamatives, so, how, extremely

\section{Introduction}

This paper is concerned with DegPs (degree phrases) such as extremely high, politically incorrect, beautifully phrased and damn important, as illustrated in (1).

(1) a. I can't believe how extremely high this building is.

b. I know how politically incorrect this decision is.

c. How beautifully phrased these lyrics are!

d. She never realized how damn important this book was to me.

All these DegPs are headed by the degree word how, which contains an adjective that is in turn modified. In the domain of the semantics of stative predicates

* I am extremely grateful to my colleagues Dongsik Lim, Norberto Moreno-Quibén and Melania Sánchez-Masià, and to the participants of the poster session of SALT 22 at U. Chicago for their insights and pertinent questions. I am responsible for any remaining mistakes. This research has been partially funded by a Ramón y Cajal Program (RYC-2010-06070) from the Spanish Ministry of Science and Innovation, and through a grant to the Project FFI2009-07114 from the same institution. 
(Maienborn 2005; Rothstein 2005; Katz 2003), the modification of adjectives by adverbs has been rarely looked at in depth (but see Ernst 2011). Mostly, whether or not a predicate can be modified by a (manner) adverb has been used as a test of eventivity. An exception to this would be the research on degree semantics, where some work has been conducted on adverbs such as surprisingly, which are construed as degree modifiers (Katz 2005; Nouwen 2005, 2011; Morzycki 2008; de Vries 2010), and to which we return in section 2. DegPs headed by how whose adjectives are modified by extremely have received some attention in the literature on exclamatives (Elliott 1974; Zanuttini \& Portner 2003; Rett 2008). For instance, the occurrence of extremely suggests that the wh-clause in (1a) conveys that the degree to which the building is high exceeds a standard of height. Even some recent literature (D'Avis 2002; Abels 2004, 2010; Castroviejo 2008; Chernilovskaya 2011) has attempted to account for the contribution of such adverbs appealing to notions such as presupposition and conventional implicature, but to this date, there is no compositional semantics of the DegP headed by how. My purpose here is twofold: First, I want to devote some time to discussing the semantic composition of these DegPs to show that their different interpretation depends on their different syntax. Second, I would like to concentrate on examples such as (1a) to understand what underlies the exclamative component that extremely contributes to $w h$-clauses.

Below are the claims that are argued for in this paper:

i. The DegPs illustrated in (1) can be classified according to how composition proceeds: extremely and beautifully pattern together in being directly modified by the degree head how; politically combines first with the adjective and then the entire adjective phrase (AdjP) is the complement of how; damn is an expressive. As such, it undergoes a separate composition and does not contribute to the main assertion.

ii. Extremely adverbs (e.g., extremely) share with Remarkably adverbs (e.g., surprisingly) a number of features, including that their core adjective is evaluative in the sense of Bierwisch (1989). However, Extremely adverbs are not propositional. They are degree predicates, where degrees are interpreted as equivalence classes of individuals (Cresswell 1976).

iii. How and so pattern together in not imposing any truth-conditional meaning constraints based on the choice of a reference point that involves an evaluation (Neeleman, van de Koot \& Doetjes 2004).

iv. The infelicity of how-interrogatives with Extremely adverbs follows from the incompatibility of the semantics of Extremely adverbs with the pragmatics of questioning (Abels 2004). 
Gradation in modified AdjPs

This paper is organized as follows: I start by sketching a few background assumptions and previous literature. In section 3, I propose a classification of the different types of DegPs according to their mode of composition, and explain how their different properties are derived. In section 4 , the focus is placed on Extremely adverbs such as extremely. ${ }^{1}$ Essentially, a comparison is established with Remarkably adverbs such as surprisingly, which leads us to the controversial issue of whether we can describe a degree as surprising or extreme. In section 5, how and so are compared to other degree words such as very. Section 6 raises the question of how and why extremely is a test for exclamativity. Section 7 wraps up and suggests future research.

\section{Background}

Throughout this paper I will assume that gradable adjectives denote relations between individuals and degrees, as shown in (2) following relatively common practice (see a.o. Seuren 1973; Cresswell 1976; von Stechow 1984; Heim 1985; Kennedy \& McNally 2005).

$$
\left[[\text { tall }]=\lambda w \lambda d \lambda x\left[\operatorname{height}_{w}(x)=d\right]\right.
$$

Above, the gradable predicate tall invokes a measure function height, which is applied to an object of type $e$ and returns the degree to which it is tall (i.e., its height).

An additional preliminary note has to do with the semantics of how-clauses. I adopt a semantics for $w h$-interrogatives $\grave{a}$ la Hamblin (1973); i.e., they denote a set of possible answers of the shape in (3).

(3) a. Bill wonders [how high this building is].

$$
\text { b. } \lambda p . \exists d\left[p=\lambda w\left[\text { height }_{w}(\text { this-building })=d\right]\right]
$$

Although not much has been said about Extremely adverbs such as extremely, some literature has focused on so-called Remarkably adverbs (Nouwen 2005, 2011; Katz 2005; Morzycki 2008; de Vries 2010). ${ }^{2}$

Morzycki (2008) notes that Remarkably adverbs such as surprisingly, incredibly or remarkably participate in complex syntactic constructions where they modify gradable adjectives, but they can also be modified, as shown in (4).

1 These do not correspond to Morzycki's (2010) Extreme degree modifiers like down-right, flat-out or full-on. I focus on deadjectival adverbs like extremely, which are themselves gradable. A few more are listed in section 4.

2 I follow Morzycki in calling them Remarkably adverbs instead of Evaluative adverbs as Nouwen and De Vries do, to avoid confusion with other notions of evaluativity such as the ones employed by Bierwisch (1989) and Rett (2008). 
(4) more remarkably tall, pretty insanely crazy, fairly embarrasingly angry

These examples deliver at least the two possible structures in (5).

a. Clyde is [[more remarkably] tall].

b. Clyde is [more [remarkably tall]].

Morzycki (2008: 4) argues that, while interpretively (5a) and (5b) do not make much of a difference, there are convincing syntactic motivations to rule out (5b). First, if the syntax were as in (5b), we would expect to obtain the ill-formed taller remarkably, as shown in (6).

(6) *Clyde is [tall-er [remarkably $t]]$.

Second, if we assume that degree modifiers are heads of a DegP and propose a structure like (5b), then we should assume too that DegPs can select in turn a DegP, which does not seem desirable, as argued by de Vries (2010). She points out that this assumption makes the wrong prediction that the sentences in (7) should be well-formed, contrary to fact.

a. *Vernon is too six feet tall.

b. *How six feet tall is Vernon?

Regarding the semantics of Remarkably adverbs, the naive idea that degrees can be described as surprising, incredible or remarkable has been convincingly ruled out. In other words, to claim that (8a) can be paraphrased as (8b) or (8c) is too simplistic and yields undesired results.

(8) From Morzycki (2008: 5)

a. Clyde is remarkably tall.

b. It's remarkable that Clyde is as tall as he is.

c. It's remarkable to be as tall as Clyde is.

Imagine Clyde is 1.30 meters tall and he is a 40 -year old male (i.e., he is quite short for his age). If what we mean by (8a) is that Clyde has a degree of tallness that is remarkable, as suggested by (8b) and (8c), then we expect that (8a) should be a good description of the imagined scenario. However, this is not the case. A more extreme case would be one where Clyde's degree of tallness coincides with the number of goals scored at the Champions League Final in 2008 (what Morzycki calls a 'freakish height'). This degree would, again, be remarkable, and yet (8a) would not be a proper way to describe this situation.

Furthermore, if we understand that degrees are positive numbers on an ordered scale, to say that a degree is remarkable or surprising or incredible makes actually no sense, as is illustrated in (9). 
Gradation in modified AdjPs

(9) ???12 is remarkable.

As claimed by Katz (2005), in sentences like (8a) there is an at least entailment, whereby it is remarkable that Clyde is at least as tall as he is. Imagine he is 2 meters tall. What (8a) expresses is that if Clyde had been any taller, this would also have counted as remarkable. Nouwen (2005) (and also Nouwen (2011) and de Vries (2010)) attributes this particular behavior to the monotonicity of both gradable adjectives and Remarkably adverbs. Monotonicity is defined as in (10).

(10) From Heim 2001

A function $f$ of type $\langle d,\langle e, t\rangle\rangle$ is monotone iff

$\forall x \forall d \forall d^{\prime}\left[f(d)(x)=1 \& d^{\prime} \prec d \rightarrow f\left(d^{\prime}\right)(x)=1\right]$

Gradable adjectives like tall are monotone in the sense that if Clyde is 2 meters tall, he is also tall to any degree below 2 meters. Nouwen points out that Remarkably adverbs construed as sentential operators $(\mathrm{O})$ are downward monotone (MON $\downarrow$ ), as defined in (11).

$$
\mathrm{O} \text { is } \mathrm{MON} \downarrow \text { iff } p=p^{\prime} \Rightarrow \mathrm{O}\left(p^{\prime}\right) \models \mathrm{O}(p)
$$

The monotonicity of gradable adjectives and the one - in the opposite direction - of Remarkably adverbs yield Katz's at least entailment. As shown in (12), remarkably behaves as a $\mathrm{MON} \downarrow \mathrm{O}$.

\section{(12) $\quad \operatorname{remarkable}\left({ }^{\wedge} \operatorname{height}(x)=d^{\prime}\right) \models \operatorname{remarkable}\left({ }^{\wedge} \operatorname{height}(x)=\left(d \succeq d^{\prime}\right)\right)$}

That is, for any individual $x$ and degrees $d$ and $d^{\prime}$ such that $d$ equals or exceeds $d^{\prime}$, if it is remarkable that $x$ is high to degree $d^{\prime}$, this entails that it is also remarkable that $x$ is high to degree $d$. This elegantly accounts for the fact that we cannot employ (8a) to express that Clyde's freakish degree of tallness is remarkable. Remarkably in this approach is a propositional operator - not a degree predicate - and its monotonicity entailments enable the expression of remarkability towards any degree starting at the actual degree of height.

Finally, we want to make sure that the entailment in (13) also holds, to avoid mapping (8a) to the first scenario depicted, where Clyde is remarkably short.

(13) remarkably tall $\models$ tall

Below I adapt de Vries's (2010) final analysis for (8a).

$$
\exists d\left[\operatorname{height}(\mathbf{c})=d \wedge d \succeq \operatorname{stnd}_{\text {tall }} \wedge \operatorname{remarkable}\left({ }^{\wedge} \operatorname{height}(\mathbf{c})=d\right)\right]
$$

In prose, (14) states that there is a degree $d$ such that Clyde is tall to degree $d$, this degree meets or exceeds the standard of tallness, and it is remarkable that 
Clyde is tall to degree $d$. As shown in (12), this by itself entails that it is remarkable that Clyde is at least as tall as he is. This proposal is able to explain the semantic idiosyncrasies of Remarkably adverbs in a simple way. In section 4, I will evaluate to what extent these ideas can be applied to Extremely adverbs.

\section{Classification of DegPs}

In this section, a classification is proposed for the examples in (1) based on the mode of composition between the degree head how, the adjective and its modifier. ${ }^{3}$ The data are classified in the three groups below:
a. Class I: [how [Adverb Adjective]]
b. Class II: [how Adjective 2] • [Adjective 1 Adjective 2]
c. Class III: [[how Adverb] Adjective]

In Class I, the adverb is a predicate modifier that combines first with the adjective, and the resulting gradable expression is the argument of how. Class II contains an expressive item in terms of Potts $(2005,2007)$. Following Potts, I assume that a parallel composition process takes place, whereby Adjective 2 (the non-expressive one) is used twice in the derivation; on the one hand, it is the argument of how and in the other hand, it is modified by Adjective 1 (the expressive item). In Class III, there is intensification of the adverb, which is gradable. In what follows, I provide a more detailed characterization of each one of the classes of composition processes.

\subsection{Class I}

The example of Class I DegPs in (1) is how politically incorrect. The main motivation for this mode of composition is that politically is not gradable, which follows from it being a domain adverb. When politically combines with correct - a gradable adjective - then the adverb-adjective combination becomes a gradable AdjP that is the argument of how. (16b) is the proposed translation of (16a).

(16) a. how politically incorrect this decision is

b. $\lambda p . \exists d\left[p=\lambda w . \exists e\left[\right.\right.$ incorrectness $_{w}(e)=d \wedge$ th $(e$, this-decision $) \wedge$ un$\operatorname{der}(e, c *) \wedge \operatorname{cr}($ political,$c *)]]$

The how-clause denotes a set of propositions that vary according to the value of $d$, which corresponds to the degree of incorrectness of an event whose theme is the

3 In this paper, I do not deal with the fine grained syntax of these constructions. I refer the interested reader to Morzycki 2008 and de Vries 2010 for two different proposals. 
Gradation in modified AdjPs

decision; importantly, this event is restricted to occur in a political domain. In (16b), I roughly adapt Ernst's (2002) analysis for domain adverbials (see also Bartsch 1987; Moltmann 1997 and Ernst 2004), where under is a covert predicate that identifies a subset of the events denoted by the main predicate, and cr is a contextual restriction on conditions $c *$ in terms of the domain made explicit by the adverb. Here, the decision can be politically incorrect, but not necessarily incorrect in other respects (for instance, the decision may be ethically correct).

\subsection{Class II}

Class II are DegPs that contain two adjectives, one being a so-called expressive (Potts 2005,2007 ) such as damn, frigging or fucking, and the other, a gradable adjective. I follow Potts in considering that at-issue content and conventionally implicated content (here instantiated by expressive meaning) run parallel computations (which is represented by the separation of a bullet $\bullet$ ). Characteristically, expressive items take as argument at-issue content and return a propositional content that does not contribute to the main assertion. (17b) is the proposed translation of (17a).

(17) a. how damn important this book is

$$
\text { b. } \left.\lambda p . \exists d\left[p=\lambda w\left[\text { importance }_{w}(\text { this-book })=d\right]\right] \bullet[[\text { damn }]]([\text { important }]]\right)
$$

What (17b) means to convey is that, on the one hand, the speaker utters She never realized how important this book was to me and, as a side comment, the speaker adds damn important. Every proposition in the set, thus, varies in the value $d$ corresponding to the importance of the book.

It is not my purpose here to delve into the semantics of expressives. In examples such as The damn machine is not working, Potts proposes that the paraphrase would be something like The speaker has a negative attitude towards the machine. When damn is modifying an adjective, it is not so clear towards what exactly the speaker is experiencing this negative attitude. ${ }^{4}$

What matters for our purposes is that the proposed composition for Class II DegPs explains why the second adjective needs to be gradable (cf. (18)) and why the expressive item follows how even if it is not gradable (cf. (19)).

4 A. Beltrama (p.c.) points out to me that whenever an expressive is modifying an adjective, the entailment is that the degree to which the property holds is high. See for instance (1).

(1) Bill is fucking tall, \# but he's not very tall / \# he's only 1.65 meters tall.

How this high degree inference is brought about is an interesting issue that deserves further research. 
(18) \#how damn weekly this magazine is

(19) a. \#very damn machine

b. \# quite frigging keys

In (18), how cannot take as argument the relational adjective weekly, because relational adjectives are typically not gradable; and (19) shows that the degree modifiers very and quite cannot intensify the expressive items damn and frigging because they are not gradable, either. Therefore, in Class II DegPs, the second adjective needs to be gradable, because this is the one that how takes as its argument.

\subsection{Class III}

Class III involves all the cases where how targets the gradability of the adverb. These include combinations of manner adverb plus participle such as beautifully phrased, Remarkably adverbs + gradable adjective combinations such as remarkably tall and Extremely adverbs + gradable adjective combinations such as extremely high.

Example (1c), repeated in (20a) for convenience, is given the analysis in (20b).

(20) a. how beautifully phrased these lyrics are

b. $\lambda p . \exists d\left[p=\lambda w . \exists e, s\left[\operatorname{phrase}_{w}(e) \wedge \operatorname{BECOME}(s)(e) \wedge \operatorname{phrased}_{w}\left(\right.\right.\right.$ these- $^{-}$ $\left.\left.\operatorname{lyrics})(s) \wedge \operatorname{beauty}_{w}(s)=d\right]\right]$

The set of propositions above vary according to the value of the degree of beauty. In each proposition there is an event $e$ and a state $s$ such that $e$ is an event of phrasing that turns into a state $s$; $s$ is a state of the lyrics being phrased, and this state is beautiful to degree $d$.

Other examples include the ones in (21).

(21) genuinely disappointed, pleasantly surprised, intensely scrutinized, highly recommended

The existence of such examples, where only the adverb is gradable, make a good case for the [[how Adverb] Adjective] composition.

Another test for this mode of composition is found in examples where both the adverb and the adjective are gradable, but it is clearly the adverb that gets intensified, as in (22a), or in examples where the adverb can hardly be coerced into a gradable property and the adjective being gradable does not make the expression acceptable, as in (22b).
a. how minimally invasive
b. \#how sufficiently different 
Gradation in modified AdjPs

Recall that in Class I, it was enough for the adjective to be gradable to make the DegP [how [Adverb Adjective]] acceptable. However, here sufficiently is not a domain adverb, so it does not pattern with politically or ethically from Class I.

\section{Extremely vs. Remarkably Adverbs}

In this section we move on to the differences and similarities between Remarkably adverbs and Extremely adverbs, that is, between examples such as (23) and examples like (24), all of which belong to Class III.

(23) crashingly bad, ridiculously expensive, insanely hot, annoyingly obsessive, unexpectedly awesome, extraordinarily depressed, surprisingly thoughtprovoking, awfully needy

(24) utterly unique, absolutely fabulous, acutely aware, deeply asleep, seriously fast, really unsuitable, glaringly obvious, highly dubious, radically simple

Throughout this section, I will consider extremely vs. surprisingly as instances of Extremely and Remarkably adverbs respectively, and I will propose a denotation for extremely. An analysis of each of the members of the list in 24 is beyond the scope of this paper.

To begin with, if we look at the core adjectives of these adverbs, we find that they share important properties. Both extreme and surprising are evaluative adjectives, in the sense of Bierwisch (1989). As such, they are norm-related. This means that any use of these adjectives implies that the subject meets or exceeds the standard of Adjective-ness. This is evident in two environments: equative comparatives and how-interrogatives, as shown in (25).

a. The drought in Arkansas is as extreme as in Arizona $\models$ The drought in Arkansas is extreme.

b. How extreme is the drought in Arkansas? $\models$ The drought in Arkansas is extreme.

These implications do not hold with dimensional adjectives like tall. Peter is as tall as Maria and How tall is Peter? are compatible with scenarios where Peter does not meet or exceed the standard of tallness.

I will follow Sassoon (2011) in treating norm-related implications of evaluative adjectives as zero-related implications. I assume with her that the domain of degrees includes a zero point, which represents the set of entities whose degree of Adjectiveness is in zero, i.e., $\left\{x \in D_{e} \mid\right.$ Adjective-ness $\left._{w}(x)=0\right\}$. She claims that the zero point can be either semantically or contextually determined, just like the cut-off point of dimensional adjectives. Evaluative adjectives are claimed to have a contextuallydetermined zero. This amounts to saying that its value varies across indices. She 
calls this a relative zero. To have zero-related implications in the case of surprising and extreme means that there is a cut-off point that teases apart what counts as surprising or extreme and what does not, and this degree is not somewhere in the middle of the scale, it is a zero degree, and one that differs in the various worlds of evaluation. We can thus state that evaluative adjectives have a minimum standard. Unlike closed-scale adjectives with a lower bound, such as empty, though, the lower bound for extreme and surprising is not encoded in the semantics of the lexical item.

Second, extremely and surprisingly share the norm-relatedness of the [Adverb Adjective] combinations. That is, the implications in (26) hold.
a. surprisingly tall $\models$ tall
b. extremely high $\models$ high

In the third place, the intensification of the adverb amounts to intensifying the adjective. In other words, the more surprising Bill's tallness is, the taller Bill is; and likewise, the more extreme the height of the building is, the higher the building is.

By contrast, surprisingly and extremely differ in non-trivial respects. For starters, Extremely adverbs do not modify propositions ((27)) or make propositional attitude predicates $((28))$.

a. Surprisingly, Bill is tall.

b. *Extremely, this building is high.

(28) a. It's surprising how tall Bill is / that Bill is so tall.

b. *It's extreme how high this building is / that this building is so high.

Furthermore, the adverb's core adjective is not always predicated of ordinary individuals in the case of Extremely adverbs, while this is possible for Remarkably adverbs, as shown in (29).

(29) a. Bill is surprising.

b. \#Bill is extreme.

What is then extreme predicated of? A simple google search returns the outcome in (30). Leaving aside the first set of examples, which are not exportable to our cases, the second set of examples shows that we can predicate extremeness of a measure function that is applied to some individual.

(30) extreme weather, exercise, diet, sports, situation but also extreme poverty, height, price, drought, idiocy of ...

Note that this boils down to saying that what counts as extreme is a degree. This can be represented as in (31). Extremely takes a gradable adjective, a degree $d$ and an 
Gradation in modified AdjPs

individual $x$, and the outcome is true iff there is a degree $d^{\prime}$ such that $x$ is $G$ to degree $d^{\prime}$, which meets or exceeds the standard of $G$-ness, and $d^{\prime}$ is extreme to degree $d$. That is, I am proposing that extreme is a gradable adjective that characterizes a degree.

$$
\left[[\text { extremely }]=\lambda G \lambda d \lambda x . \exists d^{\prime}\left[G\left(d^{\prime}\right)(x) \wedge d^{\prime} \succeq \operatorname{stnd}_{G} \wedge \operatorname{extremeness}\left(d^{\prime}\right)=d\right]\right.
$$

The denotation of (32a) is proposed to be the one in (32b).

a. how extremely high this building is
b. $\lambda p . \exists d\left[p=\lambda w \cdot \exists d^{\prime}\left[\right.\right.$ height $_{w}$ (this-building $)=d^{\prime} \wedge d^{\prime} \succeq$ stnd $_{\text {high }} \wedge$ ex- tremeness $\left.\left._{w}\left(d^{\prime}\right)=d\right]\right]$

In (32b), the alternative propositions in the set denoted by the wh-clause range over the degree $d$ of extremeness of $d^{\prime}$, construed as the building's height. Note that this proposal differs from (14), repeated below for convenience, in not treating extremely as a propositional operator, but as a degree predicate.

$$
\exists d\left[\text { height }(\mathbf{c})=d \wedge d \succeq \operatorname{stnd}_{\text {tall }} \wedge \operatorname{remarkable}(\wedge \text { height }(\mathbf{c})=d)\right]
$$

But can this be done? Recall from section 2 that it has been convincingly argued that degrees cannot be remarkable or surprising or incredible. Can they be extreme? In the previous paragraphs I have attempted to show that this seems the only way out, since they are clearly not propositional and they do not always take as argument ordinary individuals. If we look a little bit closer to the problems raised by degrees being surprising, we will realize that they have to do with our ontology. If degrees are defined as positive numbers on a scale, then we run into trouble.

What I am going to do, then, is assume an alternative definition of what a degree is. Specifically, I will follow Cresswell (1976) in treating degrees as equivalence classes of individuals, and Kaufmann in Schwager 2009, who highlights the one-toone correspondence between degrees (positive numbers or intervals) and properties (equivalence classes of individuals). Kaufmann's denotation of the height of this building is both the degree to which the building is high and the property of being as high as the building, as shown in (34).

$[[\text { The height of this building }]]_{w}=$

a. $e$ : ... the maximal degree of height $d$ s.t. height(this-building) $=d$

b. $\langle s, e t\rangle: \ldots \lambda w \lambda x . x$ is in $w$ at least as high as this building is in $w$.

The idea that degrees are equivalence classes of individuals is illustrated in Table 1 (from Schwager 2009: 504). 


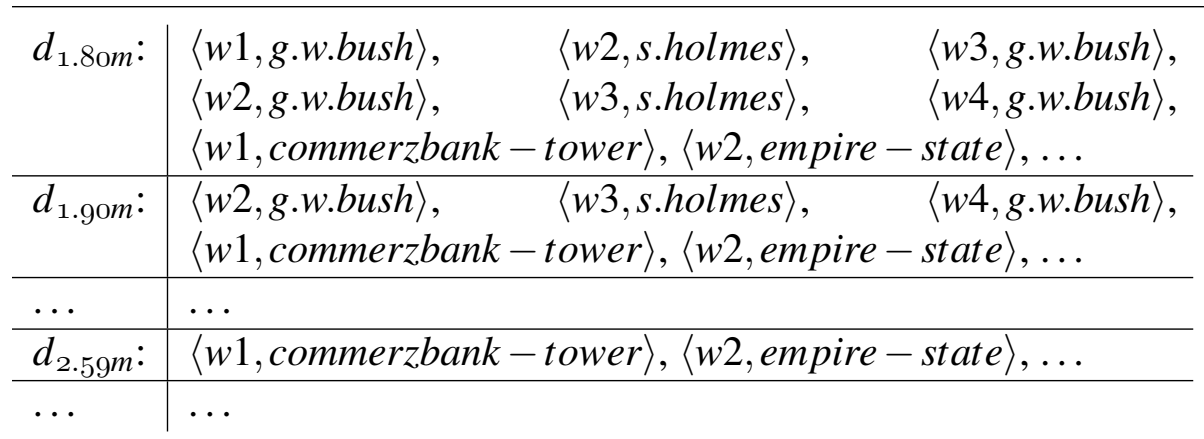

Table 1 Degrees as equivalence classes of individuals

Every degree $d$, which is labeled with a positive number, corresponds to a cell in the table, which includes pairs of worlds and individuals who are at least as high as $d$. That is to say that the height of $x$ in $w$ returns $d$ iff the pair $\langle w, x\rangle$ is in the set $d$ (cf.(35)).

$$
\operatorname{height}_{w}(x)=d \leftrightarrow\langle w, x\rangle \in d
$$

To sum up, I adopt a definition of a degree as an equivalence class of individuals, and hence a property. I am thus allowed to say that extremeness is predicated of a degree $d$ insofar as $d$ is construed as the property of being as high as the building is.

Since (31) includes the statement that $d \succeq \mathbf{s t n d}_{G}$, the height of the building cannot be any random and freakish number, and since degrees correspond to properties, sentences such as ???12 is extreme are not really an issue here.

\section{How and So}

One of the interesting repercussions the analysis of Extreme and Remarkably adverbs has concerns the semantics of the degree words that can take these adverbs as arguments. Note that if we replace how with intensifiers such as very or enough, the result is awkward. By contrast, so patterns with how, as shown in (36).

(36) If this building is so/?very/?too extremely high, then the tourists won't be able to take a picture of it.

What do these degree words have in common? In what way are very and enough different from so and how?

Neeleman et al. (2004) propose a classification of different degree expressions based on their syntactic and semantic properties. From this work, it straightforwardly follows that how and very/too/enough have a different behavior. In their account, degree expressions can be classified as evaluative or non-evaluative depending on 
whether the anchor point evoked "is related to the average degree to which a property holds of the adjective's subject", or is an "independently-specified, objective value on the adjective's scale" (Neeleman et al. 2004: 32). Examples of evaluative degree words are very, too and enough, which characteristically select for a reference point that involves an evaluation, and license for or infinitival satellites. The set of nonevaluative degree expressions includes the comparative and equative morphemes, which characteristically license as and than satellites, but also measure phrases, this/that and how.

Before focusing on (36), note that DegPs similar to the one above are allowed when instead of an Extremely adverb we have a Remarkably adverb, as is shown by de Vries (2010) and presented in (37).

pretty insanely crazy, very remarkably tall, fairly embarrassingly angry

This suggests that two factors play a role: the kind of adverb and the class of degree expression. In $\S 4$ it was pointed out that extremely is analyzed as a degree predicate. To say that a degree is very extreme requires considering a standard for extremeness applied to degrees that is contextually determined, and stating that this degree exceeds the standard to a large extent. Specifically, in $x$ is very extremely tall, the extremeness of $x$ 's tallness needs to exceed a norm based on a comparison class whose objects meet the standard for extremeness. This is probably a complicated operation that describes a scenario that speakers will hardly need to use.

However, how being non-evaluative and lacking a complex lexical content - as Neeleman et al. (2004) claim, it just asks the hearer to identify a value — the result is acceptable. Recall that in our semantics for how, the degree expression barely binds the adjective's degree argument, so each proposition has a different value for $d$.

Since so patterns with how, we are inclined to believe that so, too, is a nonevaluative degree expression. Interestingly, Neeleman et al. (2004) only bring up so as a syntactic test to identify possible syntactic structures, in examples such as John is very fond of Mary. In fact, he is more so than Bill, but they do not include it in their syntactic or semantic grouping of degree expressions. They treat so as a "categorically underspecified pro form" (Neeleman et al. 2004: 7). Nevertheless, since some of its uses are at least reminiscent of a demonstrative (see (38)) and this/that belong to the non-evaluative class, we have some motivation to group so and how together in the class of non-evaluative degree expressions.

\section{Bill is so tall. [+pointing gesture]}

This could in principle sound shocking, because intuitively so and very may seem semantically analogous in relying on an anchor point that exceeds the standard of the gradable property (cf. (39) and (40)). 
(39) Bill is so tall! / Bill is very tall. He could make a great basketball player.

(40) Bill is so tall that he reaches the first shelf. $\models$ Bill and the shelf are tall.

I consider the data in (36) as further evidence that this high degree implication is not part of so's truth-conditional semantics. Very tentatively, I will assume that demonstrative so (whose anchor is determined contextually by means of a pointing gesture, as in (38) $)^{5}$ has evolved into having an additional use where a demonstration does not contribute the anchor anymore. This is the anaphoric use illustrated in (41), which might have evolved into uses like (40). I cannot deal with these other uses here for reasons of space. Castroviejo (2011) provides a few suggestions.

\section{(41) It's amazing that Bill is so tall.}

My suggestion is that in the transition from demonstrative use to anaphoric use, the subject of the adjective needs to stand out as clearly displaying the gradable property for the matter of properly identifying the referent. I therefore consider this high degree implication a felicity condition or presupposition that has been added to the meaning of $s o$ via meaning change. That is, so, when not being employed as a demonstrative, is only felicitously used when the degree referred to is high.

So has also been equated to enough by Meier (2003). Essentially, enough and so have modal sentential complements. The default modal in so ... that constructions is the universal quantifier. When so's that-clause has an overt existential modal, then the two constructions are equivalent. For instance, the ones in (42).

(42) a. The jet flew fast enough to beat the speed record.

b. The jet flew so fast that it could beat the speed record.

However, this account does not take into consideration the high degree implication of so illustrated in (40). It also does not explain the contrast in (43).

a. This building is so extremely high that visitors see it with difficulty.

b. This building is (\#extremely) high enough that visitors see it with difficulty.

If so and enough had an equivalent meaning, we would expect enough to be able to take extremely as its complement, contrary to fact.

I then conclude that so is not an evaluative degree expression (unlike very and enough) and shares with how a meager lexical meaning (they merely bind a degree or refer to a familiar degree).

5 See Umbach \& Ebert (2009) for an analysis of "intensifying so" in German, which is argued to be a demonstrative degree modifier whose threshold or anchor point is a silent demonstration. 
Gradation in modified AdjPs

\section{Interrogatives and exclamatives}

A second interesting extension of this research on how-DegPs followed by [Adverb Adjective] combinations concerns the semantics of $w h$-interrogatives and $w h$ exclamatives. Extreme and Remarkably adverbs occur in $w h$-clauses that are taken to be exclamative sentences. Is their occurrence enough to argue that these how-clauses are exclamatives? How can the properties described above explain the behavior of these adverbs in these sentences?

To begin with, our analysis of Extremely adverbs such as extremely in (1a) should account for why they can appear in exclamative environments, unlike adverbs such as fairly, reasonably or slightly, as first noted by Elliott (1974), exemplified in (44).

\#How fairly/reasonably/slightly long he can stay under water!

The compatibility of extremely in sentences such as (44) has been used as an argument to relate exclamatives to extreme degree. Zanuttini \& Portner (2003) propose that wh-exclamatives undergo so-called domain widening, from one domain including the set of standard possible answers in a Hamblin (1973)/Karttunen (1977) question semantics, to a bigger set including non-canonical answers. In uttering (44), the speaker is considering very high degrees of length, which is compatible with describing this extent as extreme. Rett (2008), on the other hand, treats whexclamatives as evaluative constructions that convey the speaker's surprise by the high degree of a property held by a certain individual. In her account, Extremely adverbs only occur in evaluative constructions, so, again, this is compatible with the data in (44).

What remains to be figured out in both accounts is the semantic composition of the DegP including extremely, which is one of the tasks that the present paper has undertaken. Recall that it has been proposed here that how binds the degree argument of extremely. Since how takes as argument a gradable adverb, fairly, reasonably, slightly are only acceptable if they are or can be coerced into gradable predicates. Probably, it is hard to imagine that a speaker has expected a degree of length to be more fair or reasonable than it is. ${ }^{6}$ On the other hand, as has been shown in the recent literature (Rotstein \& Winter 2004; Sassoon to appear; Solt to appear), slightly only modifies absolute (instead of relative) adjectives. So slightly cannot

6 Although this is not impossible in other contexts, as shown in (1).

(1) You might be surprised how reasonably priced this gift option is for something that is hand crafted and created just for you.

$<$ www.shopatabode.com/gifts $>$ 
modify long, but it can indeed modify predicates like full, open, opaque. Consider, for instance, (45), from Chernilovskaya (2011).

(45) I've recently re-watched Season 7 and was surprised how slightly disappointed I was.

From this we can conclude that the infelicity of (44) has motivations that are independent from the claim that exclamatives convey extreme degree.

A final and related issue, which has been a matter of discussion in the literature on exclamatives (Elliott 1974; Grimshaw 1979; D'Avis 2002; Zanuttini \& Portner 2003; Abels 2004, 2010), is why extremely is infelicitous in questions, but it is felicitous in exclamatives and $w h$-clauses embedded in factive predicates, as shown in (46) and (47), respectively.

(46) \#How extremely high was this building? / \#I wonder how extremely high this building is.

(47) My son found out how extremely high this building was when we went downtown.

Grimshaw (1979) proposes that $w h$-exclamative clauses are factive, and Zanuttini $\&$ Portner (2003) go a bit further to argue that $w h$-exclamatives contain a factive morpheme that brings about domain widening when in combination with the semantics of the wh-component. Although Zanuttini \& Portner (2003) analyze very instead of extremely, the idea would be that extremely is an exclamative-only (and hence, not interrogative) part of speech. This would explain (46). As for (47), since extremely is only compatible with exclamatives and the semantics of exclamatives is triggered by a factive morpheme, this friendly environment also includes $w h$-clauses embedded in factive predicates. The question that we may pose at this point is whether we can find a more principled reason as for why extremely is exclamative-only.

D'Avis (2002) rules out cases like (46), because these sentences presuppose their own answer (Question: how high was the building? Answer: extremely high), and this would clash with the pragmatic rules of questioning. Abels $(2004,2010)$ suggests that so-called wh-clauses with intensifiers carry presuppositions that are incompatible with questioning. Similarly, Sæbø (2010) and Chernilovskaya (2011) propose that this building is extremely high is a presupposition of (46), which clashes with the asserted meaning of the embedding predicate. Finally, Castroviejo (2008) claims that Extremely adverbs in these particular configurations behave like expressives in composing with the gradable adjective in a different domain of meaning. The latter account is rejected under the present proposal, where Extremely adverbs have been argued to contribute to the at-issue domain of meaning, unlike expressives such as damn. We can still wonder whether we need to assume that the meaning conveyed by them is presuppositional. 
Gradation in modified AdjPs

First, as shown in $\S 4$, Extreme and Remarkably adverbs are evaluative, hence they have a relative zero and a minimum standard. It follows that how Adverb Adjective entails Adverb Adjective. So, (48a) implies (48b).

(48) a. I can't believe how extremely high this building is.

b. The building is extremely high.

Since these [Adverb Adjective] combinations are evaluative, we expect them to yield norm-related implications when they occur in how-interrogatives, as shown in (25) above. Also, according to the proposed denotation of extremely in (32b), predicating extremely high of $x$ involves asserting that $x$ meets or exceeds the standard of the adjective high. Therefore, when inquiring about the degree to which $x$ is extremely high (cf. (46)), the speaker is asserting that $x$ is high and is implying that $x$ is extremely high. The claim here is that the conditions for the felicity of such a question are determined to be at least as constrained as the conditions for questions about norm-related adjectives, as is the case of stupid in (49).

\#How stupid is John?

Abels (2004) shows that wh-clauses with intensifiers can appear under wonder predicates and matrix questions if they occur with a filter for presuppositions. (50) is one of his examples.

(50) If it is already this hot down there on the main floor, how unbearably hot must there be up on the balcony?

For Abels, this is evidence in favor of saying that such wh-clauses come with presuppositions incompatible with questioning. In particular, the presupposition that is filtered out in (50) would be that it must be unbearably hot in the balcony. Since inquiring about evaluative adjectives seems to behave in the same way (see (51)) we may raise the question of whether we should treat norm-related implications as presuppositions that get filtered out, or whether these contexts pave the way to make $w h$-questions with intensifiers felicitous. Specifically, by creating a context where the base line is this hot, the oddity of asking a question that also asserts hotness(the-balcony) $\succeq \mathbf{s t n d}_{h o t}$ disappears. I leave this reflection for further study.

(51) If John is this stupid and he's the smartest guy in his family, how stupid must his son be?

Since what is infelicitous is to inquire about norm-related adjectives and adverbs, we expect them to be acceptable in $w h$-clauses that are not used for this purpose. These include, on the one hand, wh-clauses embedded in factive predicates (recall (47)), because they presuppose that the subject knows the value of the $w h$ variable. And on the other hand, wh-exclamatives like (52). 
As argued for by Abels, then, rather than treating Extreme and Remarkably adverbs as exclamative-only, what they are is incompatible with questioning.

The evidence provided from Class III DegPs seems to reinforce the arguments in Abels 2004 for treating these $w h$-clauses as interrogatives. This, of course, need not (or cannot) extend to other $w h$-clauses that only make $w h$-exclamatives.

\section{Conclusions and prospects}

In this paper I have proposed that DegPs headed by how and containing modified adjectives come in three types depending on their compositional semantics. Also, I have claimed that Extremely adverbs are very similar to the more studied Remarkably adverbs, but the former cannot receive the same analysis because they are not propositional. I have argued that Extremely adverbs seem to be degree predicates. The data that has been presented is relevant to figure out the semantics of degree expressions like how and so, which pattern alike in being able to target the gradability of Extremely adverbs as opposed to other degree expressions like very and enough. I have argued that the former have little semantic content, and their high degree implication is not part of their truth-conditional meaning. As for the repercussions this research may have for the analysis of $w h$-exclamatives, it has been proposed that the norm-relatedness of Extreme and Remarkably Adverbs and the complexity of their meaning can derive their incompatibility in question environments. Thus, in principle, these adverbs identify $w h$-clauses that are not used as questions, rather than an exclamative clause type.

Among many future lines of research that derive from this paper, an interesting issue that needs to be looked at in depth is whether very in how/so very high can also be analyzed as an Extremely adverb. This would imply assuming that very in this particular configuration is a gradable predicate, because - even if only historically - it is related to an adjective with a verum reading, similar to truly and really. A story along these lines would explain why the corresponding German sehr, Spanish muy, French très or Catalan molt, which are not deadjectival, cannot occur in the place of extremely.

\section{References}

Abels, Klaus. 2004. Why surprise-predicates do not embed polar interrogatives. Linguistische Arbeitsberichte LAB 81. 203-222.

Abels, Klaus. 2010. Factivity in exclamatives is a presupposition. Studia Linguistica 64(1). 141-157. 
Gradation in modified AdjPs

Bartsch, Renate. 1987. The construction of properties under perspectives. Journal of Semantics 5(4). 293-320.

Bierwisch, Manfred. 1989. The semantics of gradation. In M. Bierwisch \& E. Lang (eds.), Dimensional Adjectives, 71-261. Springer.

Castroviejo, Elena. 2008. Adverbs in restricted configurations. In O. Bonami \& P. Cabredo Hofherr (eds.), Empirical Issues in Formal Syntax and Semantics, vol. 7, 53-76.

Castroviejo, Elena. 2011. 'So' as a weak degree expression. In N. Ashton, A. Chereches \& D. Lutz (eds.), Proceedings of SALT 21, 76-94.

Chernilovskaya, Anna. 2011. Modified degrees. Talk at the TiN Dag 2011, Utrecht.

Cresswell, Max. 1976. The semantics of degree. In Barbara Partee (ed.), Montague Grammar, 261-292. New York: Academic Press.

D'Avis, Franz-Josef. 2002. On the interpretation of wh-clauses in exclamative environments. Theoretical Linguistics 28. 5-31.

Elliott, Dale E. 1974. Toward a grammar of exclamatives. Foundations of Language 11. 231-246.

Ernst, Thomas. 2002. The Syntax of Adjuncts. Cambridge: Cambridge University Press.

Ernst, Thomas. 2004. Domain adverbs and the syntax of adjuncts. In J.R. Austin, S. Engelberg \& G. Rauh (eds.), Adverbials: The Interplay Between Meaning, Context, and Syntactic Structure, 103-129. Amsterdam: John Benjamins.

Ernst, Thomas. 2011. Modification of state predicates. Talk presented at the workshop on Modification (with \& without modifiers) - MDF2011.

Grimshaw, Jane. 1979. Complement selection and the lexicon. Linguistic Inquiry 10(2). 279-326.

Hamblin, Charles L. 1973. Questions in Montague English. Foundations of Language 10. 41-53.

Heim, Irene. 1985. Notes on comparatives and related matters. Ms, University of Texas, Austin.

Heim, Irene. 2001. Degree Operators and Scope. In C. Féry \& W. Sternefeld (eds.), Audiatur vox sapientiae. a festschrift for Arnim von Stechow, 214-239. Akademie Verlag.

Karttunen, Lauri. 1977. Syntax and semantics of questions. Linguistics and Philosophy 1. 3-44.

Katz, Graham. 2003. Event arguments, adverb selection, and the stative adverb gap. In E. Lang \& C. Fabricius-Hansen (eds.), Modifying Adjuncts, 455-474. Walter de Gruyter.

Katz, Graham. 2005. Attitudes toward degrees. In E. Maier, C. Bary \& J. Huitink (eds.), Proceedings of SuB9, 183-196.

Kennedy, Christopher \& Louise McNally. 2005. Scale structure, degree modification, 
and the semantics of gradable predicates. Language 81(2). 345-381.

Maienborn, Claudia. 2005. On the limits of the Davidsonian approach: The case of copula sentences. Theoretical Linguistics 31(3). 1-30.

Meier, Cécile. 2003. The meaning of too, enough and so...that. Natural Language Semantics 11. 69-107.

Moltmann, Friedrike. 1997. Parts and Wholes in Semantics. Oxford University Press.

Morzycki, Marcin. 2008. Adverbial modification of adjectives: Evaluatives and a little beyond. In J. Dölling \& T. Heyde-Zybatow (eds.), Event Structures in Linguistic Form and Interpretation, 103-126. Berlin: Walter de Gruyter.

Morzycki, Marcin. 2010. Adjectival extremeness: Degree modification and contextually restricted scales. Natural Language \& Linguistic Theory 1-43.

Neeleman, Ad, Hans van de Koot \& Jenny Doetjes. 2004. Degree expressions. The Linguistic Review 21(1). 1-66.

Nouwen, Rick. 2005. Monotone amazement. In P. Dekker (ed.), Proceedings of the Fifteenth Amsterdam Colloquium, 167-172. ILLC.

Nouwen, Rick. 2011. Degree modifiers and monotonicity. In P. Egré \& N. Klinedinst (eds.), Vagueness and Language Use, 146-164. Palgrave McMillan.

Potts, Christopher. 2005. The Logic of Conventional Implicatures. Oxford: Oxford University Press.

Potts, Christopher. 2007. The expressive dimension. Theoretical Linguistics 33(2). 165-197.

Rett, Jessica. 2008. Degree Modification in Natural Language: Rutgers University dissertation.

Rothstein, Susan. 2005. States and modification: A reply to Maienborn. Theoretical Linguistics 31(3). 375-381.

Rotstein, Carmen \& Yoad Winter. 2004. Total adjectives vs. partial adjectives: Scale structure and higher-order modifiers. Natural Language Semantics 12. 259-288.

Sæbø, Kjell Johan. 2010. On the semantics of embedded exclamatives. Studia Linguistica 64(1). 116-140.

Sassoon, Galit. 2011. Be positive! Norm-related implications and beyond. In I. Reich et al. (ed.), Proceedings of SuB15, 531-546.

Sassoon, Galit. to appear. The double nature of negative antonymy. In Proceedings of $\operatorname{SuB16,\text {.}}$

Schwager, Magdalena. 2009. What is amazement all about? In A. Riester \& T. Solstad (eds.), Proceedings of sub13, 499-512.

Seuren, Pietera M. 1973. The comparative. In F. Kiefer \& N. Ruwet (eds.), Generative Grammar in Europe, 528-564. Dordrecht: Reidel.

Solt, Stephanie. to appear. Comparison to arbitrary standards. In Proceedings of SuB16, . 
Gradation in modified AdjPs

von Stechow, Arnim. 1984. Comparing semantic theories of comparison. Journal of Semantics 3. 1-77.

Umbach, Carla \& Cornelia Ebert. 2009. German demonstrative so - intensifying and hedging effects. Sprache und Datenverarbeitung (International Journal for Language Data Processing) 33.

de Vries, Hanna. 2010. Evaluative degree modification of adjectives and nouns. Master's thesis. UiL-OTS.

Zanuttini, Raffaella \& Paul Portner. 2003. Exclamative clauses: At the syntaxsemantics interface. Language 79. 39-81.

Elena Castroviejo-Miró

Centro de Ciencias Humanas y Sociales (CSIC)

Calle Albasanz 26-28

28037 Madrid (Spain)

elena.castroviejo@cchs.csic.es 